\title{
Genç Futbolcularda 10 x 25 m Tekrarlı Sprint ve 10 x (2 x 12.5 m) Tekrarlı Mekik Sprint Testlerinin Güvenirliği
}

\author{
Reliability of 10 x 25 m Repeated Sprint and 10 x ( 2 x 12.5 m) Repeated Shuttle Sprint
}

Tests in Young Soccer Players

\author{
1 Tahir HAZIR \\ ${ }^{1}$ Ayşe KİN İŞLER \\ ${ }^{1}$ Yunus Emre EKİNCİ
}

${ }^{1}$ Hacettepe Üniversitesi, Spor Bilimleri Fakültesi, Egzersiz ve Spor Bilimleri Bölümü, Beytepe-Ankara

Yazışma Adresi

Corresponding Address:

Tahir Hazır

ORCID: 0000-0002-0048-0281

Hacettepe Üniversitesi, Spor Bilimleri Fakültesi, Egzersiz ve Spor Bilimleri Bölümü

E-posta: thazir@hacettepe.edu.tr

\section{öz}

Tekrarlı sprint testleri kapsamında altın standart olarak kabul edilecek bir protokol olmadığı için spor bilimleri alanında tekrarlı sprint yeteneğinin değerlendirildiği testlerin güvenirliği önemlidir. Bu çalışmanın amacı genç futbolcularda 30 sn pasif toparlanmalı $10 \times 25 \mathrm{~m}$ tekrarlı sprint testi (TST) ve $10 \times(2 \times 12.5 \mathrm{~m})$ tekrarlı mekik sprint testlerinde (TMST) ölçülen performans çıktılarının ve fizyolojik yanıtların test-tekrar test güvenirliğini belirlemektir. Çalışmaya 15 genç futbolcu (yaş: $17 \pm 0.37 \mathrm{yll}$; boy:177.2 $\pm 6.06 \mathrm{~cm}$; vücut ağırlığı:68.1 $\pm 5.86 \mathrm{~kg}$ ) gönüllü olarak katılmıştır. Katılımcılara zemini suni çim olan futbol sahasında iki hafta içinde birbirini takip eden 2-3 gün ara ile ikişer kez TST ve TMST rastgele sıra ile uygulanmıştır. Testlerde toplam sprint zamanı (TSZ), en hızı sprint zamanı (EHSZ), en yavaş sprint zamanı (EYSZ), laktik asit, kalp atım hızı ve 6 ayrı formülle yorgunluk düzeyleri elde edilmiştir. Ölçüm farklar için Bağımlı Gruplarda t Testi, güvenirlik için sınıfiçi korelasyon katsayısı (SKK), tipik hata (TH) ve varyasyon katsayısı olarak tipik hata (VK_TH) hesaplanmıştır. TMST'de tekrarlı ölçümlerde performans bileşenleri benzer bulunurken( $p>0.05)$, TST'de anlamlı fark saptanmıştır $(p<0.05)$. Her iki testte ölçülen performans bileşenleri için VK_TH \% 5 'den düşük ancak SKK TMST için orta düzeyde, TST için düşük düzeydedir. Her iki testte yorgunluk düzeylerinin hesaplandığı 6 farklı formül için VK_TH çok yüksek, SKK ise düşüktür. Her iki testte fizyolojik değişkenler için VK_TH yüksek SKK ise orta ya da yüksek düzeydedir. Bu çalışmanın bulguları genç futbolcularda TMST protokolünün TST protokolünden daha güvenilir olduğunu göstermiştir. Genç futbolcularda tekrarlı sprint performansının ve fizyolojik yanıtların değerlendirilmesinde TMST protokolü daha uygundur.

Anahtar Kelimeler: Tekrarlı sprint yeteneği, Laktik asit, Kalp atım hızı, Futbol, Güvenirlik

\section{ABSTRACT}

Since no protocol is accepted as a gold standard within the context of repeated sprint tests, reliability of the tests that evaluate repeated sprint ability is very important in sport sciences. The aim of this study was to determine the test-retest reliability of performance outputs and physiological responses measured in $10 \times 25 \mathrm{~m}$ repeated linear sprint test (RLST) and $10 \times(2 \times 12.5 \mathrm{~m})$ repeated shuttle sprint test (RST_SH) with $30 \mathrm{sec}$ passive recovery in young soccer players. Fifteen young soccer players (age:17 \pm 0.37 years; height:177.2 $\pm 6.06 \mathrm{~cm}$; body mass:68.1 $\pm 5.86 \mathrm{~kg}$ ) voluntarily participated in this study. Subjects participated in RLST and RST_SH in random order with 2-3 days intervals for each test within two weeks in an artificial turf. Total sprint time (TST), best sprint time (BST), worst sprint time (WST), lactic acid, heart rate and fatigue scores with 6 different formulas were measured for each test. For the difference between repeated measurements; paired sample t-test, for reliability; intraclass correlation coefficient (ICC), typical error (TE) and typical error as coefficient of variation (CV_TE) were measured. Performance components were parallel in repeated measurement in RST_SH(p>0.05), in RLST on the other hand there was a significant difference $(p<0.05)$. For performance components measured in both tests, CV_TE was less than $5 \%$, but ICC values were moderate for RST_SH and low for RST_S. $\mathrm{CV}_{-} \mathrm{TE}$ was unacceptably high for 6 different formulas that calculated fatigue scores in both tests, on the other hand ICC was low. For physiological variables CV_TE was high, ICC was either moderate or high in both tests. The results of the present study indicated that RST_SH protocol had higher reliability when compared with RLST in young soccer players. In addition RST_SH was found to be more suitable for evaluation of repeated sprint performance and physiological responses.

Key Words: Repeated sprint ability, Lactic acid, Heart rate, Soccer, Reliability
Geliş Tarihi (Received): 20.04.2019 Kabul Tarihi (Accepted): 07.10.2019 


\section{GíRIŞ}

Futbol çok sayıda durma, yürüme ve değiş̧ik şiddetlerde koşu gibi hareketleri içerdiği için aktivite profilinin büyük bölümü aerobik olarak tanımlanan bir takım sporudur (Mohr ve diğ., 2003). Bunun yanında bir futbol maçı, oyuncunun seviyesine bağlı olarak, düşük şiddette aktivitelerle kesintiye uğrayan, değişik sürelerde çok sayıda negatif ve pozitif ivmelenmeli tekrarlı sprintler de içermektedir (Stolen ve diğ., 2005, Bangsbo ve diğ., 1991). Bir maç esnasında oyuncular her 4-6 sn'de bir değişen 1000-1400 adet kısa süreli aktivite gerçekleştirmektedirler (Mohr ve diğ., 2003; Rienzi ve diğ., 2000; Bangsbo ve diğ., 1991). Oyuncular topa sahip olmak ya da sahada daha iyi pozisyon almak için, yaklaşık her 90 sn'de bir 2-4 sn süreli, yön değiştirme ve dönüşler içeren sprint koşuları yapmaktadırlar (Stolen ve diğ., 2005). Bunun yanında Faude ve diğ., (2012) Bundesliga maçlarında yaptıkları bir çalışmada hem gol atan ve hem de asiste eden futbolcuların en çok yaptıkları aktivitenin yön değiştirmeli koşudan çok düz sprint olduğunu belirlemişlerdir. Sprint koşuları, belirlenen sürat eşiği değerlerine bağlı olarak, maçta kat edilen toplam mesafenin \% 1-11'ini oluşturmaktadır (Stolen ve diğ., 2005).

Günümüzde, takım sporları için önemli bir performans bileşeni olduğu kabul edilen tekrarlı sprint (Andrzejewski ve diğ., 2018; Miñano-Espin ve diğ., 2017), kısa dinlenme periyotları içeren ve tekrarlı olarak maksimum sprint eforunun üretilmesini sağlayan bir yetenek olarak tanımlanmaktadır (Oliver ve diğ., 2009). Üst düzey profesyonel futbol oyuncularında bir maçta kat edilen mesafe ve tekrarlı sprint testinde (TST) ölçülen ortalama sprint zamanı arasında anlamlı yüksek ilişki saptanmıştır (Rampipini ve diğ., 2007). Ek olarak, maç analizi ile ilgili çalışmaların bulguları futbolcunun oynadığı mevkiye bağlı olarak (Di Salvo ve diğ., 2010), bir maçtaki sprint sayısı ve mesafesinin galibiyette önemli rol oynadığını da göstermiştir (Andrzejewski ve diğ., 2018; Chmura ve diğ., 2018). Bu nedenle tekrarlı sprint yeteneği, üst düzey futbol performansının değerlendirilmesinde önemli bir faktör olarak kabul edilmektedir (Impellizzeri ve diğ., 2008; Rampipini ve diğ., 2007). Bunun yanında TST'ler amatör ve profesyonel gibi farklı oyun seviyesindeki futbolcuları (Impellizzeri ve diğ., 2008), beceri düzeyinden bağımsız olarak aktif bireylerle futbolcuları (Wong ve diğ., 2012) ve genç futbolcularda da yaş gruplarını ayırt etmesi (Özdemir ve diğ.,2014; Mujika ve diğ., 2009) nedeniyle yetenek belirleme, seçme ve değerlendirmede de kullanılmaktadır (Bidaurrazaga-Letona ve diğ., 2015).

Tekrarlı sprint yeteneği, başta futbol (Mohr ve diğ., 2003) olmak üzere hokey (Spencer ve diğ., 2004), hentbol (Michalsik ve diğ., 2013) ve basketbol (Ben Abdelkrim ve diğ., 2010) gibi takım sporlarında müsabaka performansının önemli bir bileşeni olmasının yanında bu özellik, haftada birkaç antrenman yapan genç futbolcuların bireysel olarak gelişimlerinin izlenmesinde, yetenek seçimi ve belirlemede de kullanılmaktadır (Deprez ve diğ., 2015a; Deprez ve diğ., 2015b). Ek olarak TST’leri, antrenmanların ve ergojenik yardımcıların fizyolojik yanıtlara ve performans bileşenlerine etkisini gözlemlemek için oluşturulan araştırma desenlerinde de bir egzersiz tipi olarak da sıklıkla kullanılmaktadır (Kopec ve diğ., 2016; Beaven ve diğ., 2013; Spencer ve diğ., 2011). Buna karş1lık uygulanan testlerin sprint tipi (koşu veya bisiklet), süresi (bisiklet), mesafesi (koşu), tekrar sayısı ve toparlanma tipi ve süresi çok farklı olduğu için altın standart bir protokol mevcut değildir (Spencer ve diğ., 2005). Bu nedenle geçerliği ve güvenirliği yüksek test protokollerinin kullanılması önem taşımaktadır. Farklı TST protokollerinin geçerliği ile ilgili birçok çalışma yapılmış olmakla beraber (Barbero-Álvarez ve diğ., 2013; Impellizzeri ve diğ., 2008; Bishop ve diğ., 2001), bu testlerde ölçülen güç çıktılarının ve yorgunluğun değerlendirilmesinde kullanılan çok sayıdaki farklı formüllerin güvenirliği ile ilgili çalışma çok azdır. Benzer şekilde gerek sahada gerekse laboratuvarda farklı TST protokollerinin güvenirliği daha çok performans çıktıları üzerinden değerlendirilmiş, bu testlere verilen fizyolojik yanıtların güvenirliğine çok fazla yer verilmemiştir. Buradan hareketle bu çalışmanın amacı düz koşu içeren $10 \times 25 \mathrm{~m}$ tekrarlı sprint testinin (TST) ve $180^{\circ}$ dönüş içeren $10 \times(2 \times 12.5 \mathrm{~m})$ tekrarlı mekik sprint testinin (TMST) performans bileşenlerinin, yorgunluğun 
değerlendirilmesinde kullanılan 6 ayrı formülün ve kalp atım hızı (KAH) ve kan laktat (LA) yanıtlarının test-tekrar test güvenirliğini belirlemektir.

\section{YÖNTEM}

Araştırma Grubu: Bu araştırmaya, Spor Toto Gelişim Liglerinde en az 3 yıldır futbol oynayan alt ekstrermite yaralanması olmayan 15 genç futbolcu gönüllü olarak katılmıştı (Boy: $177.2 \pm 6.1 \mathrm{~cm}$, VA: $68.1 \pm 5.9 \mathrm{~kg}$, Yaş: $17 \pm 0.37$ yıl, Spor yaşı: $6.73 \pm 0.59$ yıl). Çalışmaya katılan futbolculara ve antrenörlerine çalışmanın amaçları, yöntemi, sağlayacağ1 katkılar ve çalışma sırasında oluşabilecek olası riskler konusunda ayrıntılı bilgi verilmiş ve futbolculara aydınlatılmış onam formu imzalatılmıştır. Çalışmaya başlamadan önce çalışma için Girişimsel Olmayan Klinik Çalışmalar Etik Kuruldan onay alınmıştır (Proje No: GO 19/145).

İşlem Yolu: Bu çalışmanın verileri 4 aşamalı olarak toplanmıştır. Katılımcılara birbirini takip eden 2-3 gün ara sonrasında 2 kez TST ve bir hafta sonra aynı aralıklarla 2 kez TMST protokolü rastgele sıra ile uygulanmıştır. Tüm testler suni çim olan futbol sahasında yapılmıştır. Her iki testte de sprintler arasında 30 sn pasif dinlenme verilmiştir. Her bir test öncesinde bir kondisyoner tarafından antrenmandan önce yaptırılan rutin ısınma uygulanmış ve araştırmacılar da testlerin tanıtımı ve gerekli açıklamaları yapmıştır. Testler öncesinde, süresince ve toparlanma sırasında kalp atım hızı (KAH) kaydedilmiş ve yine test öncesi, hemen sonrası ve test sonu 3. dk'da kan laktik asit konsantrasyonu ölçülmüştür. Katılımcılardan testlerden önceki 24 saat içinde herhangi bir fiziksel aktivite yapmamaları istenmiştir. Sirkadiyen ritmin etkisini sabitlemek için tüm testler günün aynı saatinde (14.00-16.00) (Racinais ve diğ., 2005) ve aynı yerde yapılmıştır. Katılımcılar tüm testlere aynı spor malzemeleri (ayakkkabı, şort, tişört) ile girmişlerdir.

\section{Verilerin Toplanması}

Boy Uzunluğu ve Vücut Ăğırlı̆̆ı: Boy uzunluğu sahada duvara monte edilen kayan kaliper (Holtain Ltd, UK) yardımıyla $\pm 0.1 \mathrm{~cm}$ ölçüm hassasiyeti ile katılımcı anatomik duruşta iken inspirasyonu takiben alınmıştır. Vücut ağırlığ 1 $\pm 0.1 \mathrm{~kg}$ ölçüm hassasiyeti ile spor kıyafeti giymiş halde ve ayakkabısız olarak banyo baskülü (Seca, Germany) üzerinde anatomik duruşta iken ölçülmüştür.

\section{Tekrarlt Sprint Testleri}

Tekrarlı Düz Sprint ve Mekik Sprint Testi: TST sprintler arasinda 30 sn toparlanmalı 10 x 25 m, TMST ise yine 30 sn toparlanmalı $10 \times(2 \times 12.5 \mathrm{~m})$ protokolünden oluşmaktadır. TST için düz bir hat üzerinde belirlenen 25 metre mesafenin başlangıç ve bitiş noktalarına \pm 0.01 sn hassasiyetle ölçüm yapan iki kapılı fotoselli elektronik kronometre sistemi (Tümer Elektronik Ltd, Ankara, Türkiye) yerleştirilmiştir. TMST 12.5 metre gidiş ve $180^{\circ}$ yön değiştirmeyi takiben 12.5 metre dönüş olmak üzere toplam 25 m'den ibarettir. Başlangıç noktasına ve 12.5 metrede dönüş noktasına koyulan konilerle işaretlenen suni çim olan futbol sahasında hem başlangıç hem de bitişi olan çizgiye TST protokolünde kullanılan fotoselli elektronik kronometre sistemi (Tümer Elektronik Ltd, Ankara, Türkiye) yerleştirilmiştir. Katılımcılara test protokollerinin uygulandığ ilk gün $3 \mathrm{dk}$ ara ile $2 \mathrm{kez}$ maksimal deneme yaptırılmış ve en iyi sprint zamanları kayıt edilmiştir (Castagna ve diğ., 2018). Katılımcılar 5 dk pasif olarak dinlendirildikten sonra testler uygulanmıştır (Castagna ve diğ., 2018). Her iki test protokolünün ilk sprintinde en iyi sprint zamanının \% 95'inden daha yavaş koşan katılımcı strateji geliştirdiği kabul edilerek en az 5 dk dinlendirilmiş ve sonra test tekrarlanmıştır (Girard ve diğ., 2011). Tüm katılımcılar her iki testte de ilk sprint zamanını en iyi sprint zamanlarının \% 95'inin üstünde koşmuşlardır. Katılımcılar testlere başlangıç noktasının $50 \mathrm{~cm}$ arkasından çıkış yapmışlardır. TST protokolünde bitiş çizgisini geçtikten sonra yürüyerek başlangıç noktasına yürüyerek dönmüşlerdir (Castagna ve diğ., 2008). TMST test protokolünde $12.5 \mathrm{~m}$ 
koştuktan sonra $180^{\circ}$ dönerek başlangıç çizgisinden çıkmışlardır. Katılımcılar her bir sprint esnasında sözel olarak motive edilmişlerdir. Testi bitirme zamanları sn cinsinden kaydedilmiştir. Her iki protokol için performans bileşeni olarak toplam sprint zamanı (TSZ), en hızlı sprint zamanı (EHSZ) ve en yavaş sprint zamanı (EYSZ) dikkate alınmıştır.

Yorgunluğun Değerlendirilmesi: Her iki testte (TST ve TMST) yorgunluk 6 ayrı formül kullanılarak hesaplanmıştır. Yorgunluğun değerlendirilmesinde kullanılan formüller aşağıda verilmiştir:

Formül 1 (F1): Yorgunluk = İlk ve son sprintler arasında zaman artış yüzdesi

Hesaplama: Yorgunluk $=(($ Sprint10 - Sprint 1$) \div$ Sprint 1) $\times 100$

Formül 2 (F2): Yorgunluk = En hızlı ve en yavaş sprintler arasındaki zaman artış yüzdesi Hesaplama: Yorgunluk = $(($ en yavaş sprint - en hızlı sprint) $\div$ en hızlı sprint) x 100

Formül 3(F3): Yorgunluk = Sprintte Düşüş Yüzdesi

Hesaplama: Yorgunluk $=(100 \times($ toplam sprint zamanı $\div$ ideal sprint zamanı $))-100$

Toplam sprint zaman1 $=1$. sprint +2. sprint $+\ldots . .10$. sprint

İdeal sprint zamanı $=$ Sprint Sayı1 $x$ En iyi sprint zamanı.

Formül 4 (F4): Yorgunluk = En hızlı iki ve en yavaş iki sprint zamanı ortalaması arasındaki zaman yüzde artışı

Hesaplama: Yorgunluk $=((($ En yavaş iki sprint süresi $\div 2)-($ en hızlı iki sprint süresi $\div 2)) \div($ en hızlı iki sprint süresi $\div$ 2)) $\mathrm{x} 100$

Formül 5 (F5): Yorgunluk = İlk iki sprintin ortalama zamanı ve son iki sprintin ortalama zamanı arasındaki farkın ilk iki sprint ortalama zamanına yüzde oranı.

Hesaplama: Yorgunluk $=((($ Sprint $1+$ Sprint 2$) \div 2)-(($ Sprint $9+$ Sprint 10) $\div 2)) \div(($ Sprint $1+$ Sprint 2$) \div 2)) \times 100$

Formül 6 (F6): Yorgunluk = İlk iki sprint zamanının ortalamasının ortalama sprint zamanına yüzde oranı

Hesaplama: Yorgunluk $=((($ Toplam sprint zaman $1 \div 10) \div(($ Sprint $1+$ Sprint2 $) \div 2)) \times 100)-100$

Laktik Asit Analizi: $\quad$ TST ve TMST'de kan LA konsantrasyonu elektroenzimatik yöntemle ölçüm yapan cihazla (YSI Sport 1500, USA) belirlenmiştir. Kan LA konsantrasyonları 1sınmaya başlamadan önce (LA $A_{\text {Din }}$ ), testten hemen sonra $\left(\mathrm{LA}_{\mathrm{TS}}\right)$ ve testlerin bitimini takip eden 3. dk'da (LA 3.dk) kulak memesinden alınan 40-50 $\mu 1$ kandan analiz edilerek mmol. $\mathrm{L}^{-1}$ cinsinden kayıt edilmiştir.

Kalp Atım Hızı: KAH, bir telemetrik kalp atım hızı monitörü (S610i, Polar Electro Oy, Kempele, Finland) kullanılarak her iki testte 1sınma öncesinde en az $10 \mathrm{dk}$ oturur pozisyonda dinlendirildikten sonra $\left(\mathrm{KAH}_{\text {Din }}\right)$, testler esnasında $\left(\mathrm{KAH}_{\text {Test }}\right)$ ve testlerin bitimini takip eden 3. dk'ya $\left(\mathrm{KAH}_{3 . \mathrm{dk}}\right)$ kadar 5 sn aralıklarla kayıt edilmiştir. Kayıt edilen KAH verileri Polar Pro Trainer 5 yazılım programına aktarılmıştır. Test boyunca ölçülen KAH değerlerinin ortalaması $\mathrm{KAH}_{\text {Test }}$ ve testten sonra 3. dk'da ölçülen $\mathrm{KAH}_{3 . \mathrm{dk}}$, toparlanma $\mathrm{KAH}$ olarak dikkate alınmıştır.

Verilerin Analizi: Değişkenlerin normal dağılıma uyumu Kolmogorov-Smirnov Testi ile kontrol edilmiştir. Tüm değişkenler için normal dağılımdan sapma önemsiz bulunmuştur ( $p>0.05)$. Değiş̧kenlerin tanımlayıcı istatistikleri yapıldıktan sonra (ortalama \pm SD), tekrarlı ölçümler arasındaki farklar için bağımlı gruplarda $t$ testi kullanılmıştır. Testtekrar test ölçümlerinin oransal (relatif) güvenirliği için Two-way Random Effects $(2,1)$ modeli kullanılarak sınıf içi 
korelasyon katsayıları (SKK) hesaplanmış (Atkinson ve Nevill, 1998) ve SKK 0.5'den düşükse zayıf, 0.5-0.75 arasında orta, 0.75-0.90 arasında iyi, 0.90'dan yüksekse mükemmel olarak sınıflandırılmıştır (Koo ve Li, 2016). Ölçümden ölçüme bireysel seviyede ortaya çıkan değişkenliğin mutlak ve oransal olarak değerlendirilmesi için tipik hata (TH) ve varyasyon katsayısı olarak tipik hata (VK_TH) hesaplanmıştır (Hopkins, 2000). TH’nın hesaplanması için TH $=$ SD $/ \sqrt{ } 2$ formülü kullanılmıştır. Formülde SD: Tekrarlı ölçümlerin farklarının standart sapmasıdır. VK_TH'nın hesaplanması için önce tüm değişkenlere logaritmik dönüşüm uygulanmış ve sonra $100\left(\mathrm{e}^{\mathrm{SD} / 100}-1\right)$ formülünden VK_TH hesaplanmıştır. Formülde e: Doğal logaritma, SD: Tekrarlı ölçümlerin farklarının standart sapmasıdır. TH ve VK_TH hesaplamak için "xrely.xls" excel yazılımı (https ://www.sportsci.org/resource/stats/) kullanılmıştır. Yüzde beş ve daha düşük VK_TH, bireysel seviyede değişkenlik (güvenirlik) için kabul edilebilir düzey olarak değerlendirilmiştir (Hopkins, 2000). Her hangi bir formülden yorgunluk düzeyi hesaplandığında iki ölçümden birinde negatif, diğerinde pozitif değerler elde edilen katılımcılar değerlendirmeden çıkarılmış, iki ölçümde de negatif yorgunluk düzeyi verenlerin değerleri pozitife çevrilerek işlem yapılmıştır (Glaister ve diğ., 2008). TST protokolünde test-tekrar test ölçümlerinden elde edilen verilerden F1 formülü ile hesaplanan yorgunluk düzeyi 1 denekte -/+, F6 formülü ile hesaplanan yorgunluk düzeyi ise 3 katılımcıda /+, 1 katılımcıda -/- hesaplanmıştır. TMST protokolünde test-tekrar test ölçümlerinden elde edilen verilerden F1 formülü ile hesaplanan yorgunluk düzeyi 2 katılımcıda -/+, F3 formülünde 1 katılımcıda, F6 formülünde 4 katılımcıda -/+, 1 katılımcıda -/- hesaplanmıştır. Bu nedenle tüm istatistik işlemlerde TST'de F1 için n = 14, F6 için n=12; TMST'de ise $\mathrm{F} 1$ için $\mathrm{n}=13$, F3 için $\mathrm{n}=14, \mathrm{~F} 6$ için $\mathrm{n}=11$ 'dir. Tüm istatistik analizler ve hesaplamalar Excel ve SPSS (Ver. 15) programlarında yapılmış ve istatistik analizlerde $\mathrm{p}=0.05$ yanılma düzeyi kullanılmıştır.

\section{BULGULAR}

TST ve TMST protokollerinin performans bileşenlerinin tekrarlı ölçümleri Tablo 1'de, farklı formüllerle ölçülen yorgunluk düzeyleri Tablo 2'de gösterilmiştir. TST protokolünde ikinci testte ölçülen TSZ, EHSZ ve EYSZ istatistiksel olarak anlamlı derecede kısadır $(\mathrm{p}<0.013)$. Buna karşılık $180^{\circ}$ yön değiştirme içeren TMST protokolünde tekrarlı ölçümler arasında fark saptanmamıştır.

Tablo 1. TST ve TMST protokollerinde ölçülen performans bileşenlerinin tanımlayıcı istatistikleri ve t-testi sonuçları.

\begin{tabular}{|c|c|c|c|c|c|c|}
\hline & \multicolumn{2}{|c|}{ TST } & \multicolumn{4}{|c|}{ TMST } \\
\hline & TEST 1 & TEST 2 & $\mathbf{p}$ & TEST 1 & TEST 2 & $\mathbf{p}$ \\
\hline TSZ (sn) & $38.08 \pm 1.63$ & $36.27 \pm 1.93$ & 0.000 & $51.83 \pm 1.84$ & $51.15 \pm 2.01$ & 0.149 \\
\hline $\begin{array}{l}\text { EHSZ } \\
\text { (sn) }\end{array}$ & $3.63 \pm 0.16$ & $3.52 \pm 0.18$ & 0.013 & $5.00 \pm 0.16$ & $4.98 \pm 0.17$ & 0.527 \\
\hline $\begin{array}{l}\text { EYSZ } \\
\text { (sn) }\end{array}$ & $3.96 \pm 0.18$ & $3.73 \pm 0.22$ & 0.000 & $5.39 \pm 0.27$ & $5.27 \pm 0.26$ & 0.086 \\
\hline
\end{tabular}

TST: Tekrarlı Sprint, TMST: Tekrarlı Mekik Sprint, TSZ: Toplam Sprint Zamanı, EHSZ: En Hızlı Sprint Zamanı, EYSZ: En Yavaş Sprint Zaman1

Benzer şekilde TST protokolünde F5'den hesaplanan yorgunluk düzeyi hariç diğer formüllerden hesaplanan yorgunluk düzeyleri ikinci ölçümden düşüktür. TMST protokolünde ise hesaplanan yorgunluk düzeylerinin ölçümden ölçüme değişkenliği TST protokolünden azdır. Bu protokolde sadece F3 ve F6 formüllerinden hesaplanan yorgunluk düzeyleri ikinci ölçümlerden istatistiksel olarak anlamlı derecede düşüktür ( $\mathrm{p}<0.040)$. TMST protokolünde F1, F2, F4 ve F5 formüllerinden hesaplanan yorgunluk düzeyleri benzer bulunmuştur. 
Tablo 2. TST ve TMST protokollerinde farklı formüllerle ölçülen yorgunluk düzeylerinin tanımlayıcı istatistikleri ve ttesti sonuçları.

\begin{tabular}{lllllll}
\hline & \multicolumn{2}{c}{ TST } & p & \multicolumn{2}{c}{ TMST } & p \\
\hline F1 $(\mathbf{n}=\mathbf{1 4 / 1 3})$ & $6.3 \pm 3.5$ & $3.7 \pm 2.8$ & 0.032 & $4.4 \pm 3.6$ & $2.8 \pm 1.8$ & 0.079 \\
F2 $(\mathbf{n}=\mathbf{1 5} / \mathbf{1 5})$ & $9.1 \pm 3.2$ & $5.7 \pm 2.0$ & 0.001 & $7.8 \pm 4.09$ & $5.8 \pm 1.6$ & 0.076 \\
F3 $(\mathbf{n}=\mathbf{1 5 / 1 4})$ & $4.9 \pm 2.3$ & $2.8 \pm 1.1$ & 0.004 & $3.7 \pm 1.5$ & $2.7 \pm 0.5$ & 0.030 \\
F4 (n= 15/15) & $6.9 \pm 2.4$ & $4.6 \pm 1.6$ & 0.001 & $5.9 \pm 3.0$ & $4.9 \pm 1.7$ & 0.181 \\
F5 (n= 15/15) & $3.8 \pm 1.2$ & $4.2 \pm 1.0$ & 0.299 & $5.8 \pm 1.6$ & $5.5 \pm 1.0$ & 0.709 \\
F6 $(\mathbf{n}=\mathbf{1 2 / 1 1})$ & $2.9 \pm 2.0$ & $1.9 \pm 1.1$ & 0.020 & $2.4 \pm 2.0$ & $1.2 \pm 1.0$ & 0.040 \\
\hline
\end{tabular}

TST: Tekrarlı Sprint, TMST: Tekrarlı Mekik Sprint, $\mathrm{n}=$ TST/TMST

Tablo 3. TST ve TMST protokollerinde ölçülen LA ve KAH değerlerinin tanımlayıcı istatistikleri ve t-testi sonuçları.

\begin{tabular}{|c|c|c|c|c|c|c|}
\hline & \multicolumn{2}{|c|}{ TST } & \multicolumn{4}{|c|}{ TMST } \\
\hline & TEST 1 & TEST 2 & $\mathbf{p}$ & TEST 1 & TEST 2 & p \\
\hline $\begin{array}{l}\text { LA }_{\text {Din }} \text { (mmol.L' } \\
\text { 1) }\end{array}$ & $1.10 \pm 0.35$ & $1.02 \pm 0.26$ & 0.436 & $1.01 \pm 0.27$ & $1.12 \pm 0.23$ & 0.119 \\
\hline $\mathbf{L A}_{\mathrm{TS}}\left(\mathbf{m m o l . \mathbf { L } ^ { - 1 } )}\right.$ & $10.16 \pm 2.80$ & $8.80 \pm 1.79$ & 0.007 & $9.45 \pm 2.20$ & $8.40 \pm 1.54$ & 0.029 \\
\hline $\begin{array}{l}\text { LA3.dk (mmol.L' } \\
\text { 1) }\end{array}$ & $10.15 \pm 2.50$ & $9.33 \pm 2.42$ & 0.076 & $9.96 \pm 2.63$ & $8.74 \pm 1.95$ & 0.047 \\
\hline $\begin{array}{l}\text { KAH }_{\text {Din }} \\
\text { (atım.dk }^{-1} \text { ) }\end{array}$ & $85.4 \pm 9.0$ & $88.5 \pm 6.6$ & 0.148 & $86.8 \pm 7.9$ & $86.5 \pm 4.9$ & 0.954 \\
\hline $\begin{array}{l}\text { KAH }_{\text {Test }} \\
\left(\text { atım.dk }^{-1}\right)\end{array}$ & $176.6 \pm 12.4$ & $175.1 \pm 10.4$ & 0.427 & $172.7 \pm 11.3$ & $171.3 \pm 10.6$ & 0.506 \\
\hline $\begin{array}{l}\text { KAH3.dk } \\
\text { (atım.dk }\end{array}$ & $116.2 \pm 14.6$ & $115.0 \pm 10.7$ & 0.534 & $113.7 \pm 9.1$ & $109.0 \pm 8.0$ & 0.054 \\
\hline
\end{tabular}

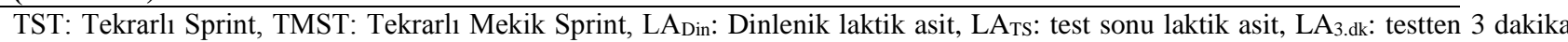
sonraki laktik asit, $\mathrm{KAH}_{\text {Din: }}$ Dinlenik kalp atım hızı, $\mathrm{KAH}_{\text {Test: }}$ test esnasında ölçülen kalp atım hızı, $\mathrm{KAH}_{3 . \mathrm{dk}}$ : Testten 3 dakika sonra ölçülen kalp atım hızı

TST ve TMST protokollerinde ölçülen LA ve KAH değerleri Tablo 3'de verilmiştir. Her iki protokolde dinlenik, test esnasında ve toparlanmanın 3. dk'sında ölçülen test-tekrar test KAH değerleri arasında anlamlı fark saptanmamıştır. Buna karşılık her iki protokolde ikinci ölçümlerde elde edilen test sonu kan LA konsantrasyonları ilk ölçümlerden istatistiksel olarak anlamlı derecede düşüktür $(\mathrm{p}<0.029)$. TMST protokolü sonrasında toparlanmanın 3.dk’sında ölçülen kan LA konsantrasyonu da ilk ölçümden istatistiksel olarak anlamlı derecede düşük bulunmuştur $(\mathrm{p}<0.047)$.

Tablo 4. TST ve TMST protokollerinde TSZ, EHSZ ve EYSZ değerleri için hesaplanan SKK, TH ve VK_TH değerleri.

\begin{tabular}{lccc}
\hline TST & TSZ & EHSZ & EYSZ \\
\hline TH (sn) & 0.93 & 0.10 & 0.11 \\
VK_TH (\%) & 2.6 & 2.0 & 2.9 \\
SKK & 0.49 & 0.56 & 0.43 \\
SKK \% 95 GA & $-0.11-0.82$ & $0.06-0.83$ & $-0.11-0.79$ \\
\hline TMST & & & \\
\hline TH (sn) & 1.22 & 0.11 & 0.18 \\
VK_TH (\%) & 1.9 & 1.9 & 2.8 \\
SKK & 0.75 & 0.74 & 0.69 \\
SKK \% 95 GA & $0.25-0.92$ & $0.24-0.91$ & $0.08-0.90$ \\
\hline
\end{tabular}

TH: Tipik hata, VK_TH: Varyasyon katsayısı olarak tipik hata, SKK: Sınıfiçi korelasyon katsayısı, \% 95 GA: \% 95 güven aralığı, TSZ: Toplam sprint zamanı, EHSZ:En hızlı sprint zamanı, EYSZ: En yavaş sprint zamanı 
Tablo 5. TST ve TMST protokollerinde ölçülen LA ve KAH değerleri için hesaplanan SKK, TH ve VK_TH değerleri.

\begin{tabular}{|c|c|c|c|c|c|c|}
\hline TST & LADin & $\mathbf{L A t s}_{\mathrm{T}}$ & LA3.dk & KAHDin $_{\text {Din }}$ & KAHTest & $\mathrm{KAH}_{3 . \mathrm{dk}}$ \\
\hline TH & 0.2 & 1.2 & 1.2 & 5.7 & 4.9 & 4.9 \\
\hline VK_TH & 27.7 & 10.2 & 12.8 & 7.3 & 2.8 & 4.7 \\
\hline SKK & 0.35 & 0.67 & 0.75 & 0.62 & 0.82 & 0.86 \\
\hline$\% 95$ GA & $-0.18-0.72$ & $0.13-0.89$ & $0.39-0.91$ & $0.17-0.86$ & $0.55-0.94$ & $0.64-0.95$ \\
\hline \multicolumn{7}{|l|}{ TMST } \\
\hline TH & 0.2 & 1.2 & 1.5 & 8.3 & 5.3 & 6.1 \\
\hline VK_TH & 14.5 & 13.3 & 18.6 & 11.3 & 3.1 & 6.7 \\
\hline SKK & 0.73 & 0.76 & 0.72 & 0.68 & 0.87 & 0.67 \\
\hline$\% 95$ GA & $0.20-0.91$ & $0.29-0.92$ & $0.17-0.91$ & $0.26-0.89$ & $0.61-0.96$ & $0.02-0.89$ \\
\hline
\end{tabular}

LADin: Dinlenik laktik asit, LATs: test sonu laktik asit, LA3.dk: testten 3 dakika sonraki laktik asit, KAHDin: Dinlenik kalp atım hızı, KAHTest: test esnasında ölçülen kalp atım hızı, KAH3.dk: Testten 3 dakika sonra ölçülen kalp atım hızı, TH: Tipik hata, VK_TH: Varyasyon katsayısı olarak tipik hata, SKK: Sınıfiçi korelasyon katsayısı, \% 95 GA: \% 95 güven aralığı.

Her iki protokolde performans bileşenleri için SKK, TH ve VK_TH Tablo 4'de, metabolik ve fizyolojik yanıtlar için SKK, TH ve VK_TH Tablo 5'de sunulmuştur. TST protokolünde elde edilen performans bileşenlerinin SKK, $180^{\circ}$ dönüş içeren TMST protokolünden düşüktür. Bununla beraber her iki protokolde performans bileşenleri için tekrarlı ölçümlerde bireysel seviyede mutlak değişkenliğin göstergesi olan TH çok küçük, oransal göstergesi olan VK_TH \% 5 'den düşüktür.

TST ve TMST protokollerinde ölçülen sprint düzeylerinden 6 ayrı formülle hesaplanan SKK, TH ve VK_TH Tablo 6'da gösterilmiştir. Her iki protokolde tüm formüllerin SKK düşük ve VK_TH değerleri TST protokolü için \% 28 ile 129.4 , TMST protokolü için \% 31.4 ile 119.2 gibi kabul edilemez bir aralıkta değiştiği gözlenmiştir.

Tablo 6. TST ve TMST protokollerinde farklı formüllerle ölçülen yorgunluk düzeyleri için hesaplanan SKK, TH ve VK_TH değerleri.

\section{TST}

\begin{tabular}{lcccccc} 
& F1 & F2 & F3 & F4 & F5 & F6 \\
\hline TH (\%) & 2.9 & 2.2 & 1.6 & 1.4 & 1.3 & 0.9 \\
VK_TH (\%) & 129.4 & 34.2 & 49.9 & 28.3 & 46.7 & 52.0 \\
SKK & 0.12 & 0.19 & 0.10 & 0.33 & -0.27 & 0.58 \\
\%95 GA & $-0.26 / 0.54$ & $-0.13 / 0.56$ & $-0.18 / 0.48$ & $-0.11 / 0.70$ & $-0.67 / 0.27$ & $0.02 / 0.86$
\end{tabular}

TMST

\begin{tabular}{lcccccc} 
& F1 & F2 & F3 & F4 & F5 & F6 \\
\hline TH & 2.02 & 2.83 & 1.10 & 2.06 & 1.56 & 1.23 \\
VK_TH & 119.2 & 41.4 & 41.6 & 36.1 & 31.4 & 183.4 \\
SKK & 0.45 & 0.15 & 0.21 & 0.27 & -0.40 & 0.34 \\
\%95 GA & $-0.04 / 0.78$ & $-0.27-0.58$ & $-0.19 / 0.61$ & $-0.21 / 0.67$ & $-0.82 / 0.17$ & $-0.15 / 0.75$
\end{tabular}

TH: Tipik hata, VK_TH: Varyasyon katsayısı olarak tipik hata, SKK: Sınıfiçi korelasyon katsayısı, \% 95 GA: \% 95 güven aralığı. 


\section{TARTISSMA}

$\mathrm{Bu}$ çalışmada genç erkek futbolcularda düz koşu içeren 10x25 m TST ve $180^{\circ}$ dönüşlü 10 x $(2 \times 12.5 \mathrm{~m})$ TMST test protokollerinde TSZ, EHSZ ve EYSZ'nı içeren performans çıktılarının ve kan LA ve KAH'nı içeren fizyolojik yanıtların test-tekrar test güvenirliği incelenmiştir. Bu çalışmada ayrıca her iki protokol için bir diğer performans çıktısı olan ve tekrarlanan sprintlerin kalitesini yansıtan yorgunluk düzeylerinin hesaplanmasında kullanılan 6 farklı formülün güvenirliği de incelenmiştir. Bu çalışmanın ana bulgusu, genç erkek futbolcularda, içerisinde $180^{\circ}$ dönüş bulunan tekrarlı sprint protokolünün düz koşu içeren protokole göre hem performans hem de fizyolojik yanıtlar açısından test-tekrar test güvenirliğinin daha yüksek olduğunu göstermiştir. Ek olarak bu çalışmanın bulguları her iki protokolde kaydedilen sprint zamanlarından 6 ayrı formülle hesaplanan yorgunluk düzeylerinin tümünün test-tekrar test güvenirlik özelliklerinin kabul edilemez düzeyde düşük bulunması, bu parametrenin tekrarlanan sprintlerin kalitesindeki değişimi yorumlamada pratik kullanım değerinin düşük olduğunu göstermiştir.

Futbolda maç performansı ve maç sonucu ile tekrarlı sprint yeteneği arasında ilişki bulunması (Andrzejewski ve diğ., 2018; Chmura ve diğ., 2018; Barbero-Álvarez ve diğ., 2013; Rampipini ve diğ., 2007) bu özelliğin elit futbol performans1 için önemli olduğunun bir göstergesidir. Bununla beraber uygulamada herkesin kabul ettiği bir protokolün mevcut olmaması, tekrarlı sprint uygulamalarında elde edilen performans çıktılarının güvenirliğinin sistematik bir şekilde incelenmesini gerektirir. Bu çalışmada TMST protokolünde tekrarlı ölçümlerde TSZ, EHSZ ve EYSZ'da anlamlı fark saptanmamış buna karşılık TST'de ikinci ölçümlerde tüm parametrelerde anlamlı derecede daha iyi değerler kayıt edilmiştir (Tablo 1). Her iki protokol için VK_TH'nın tüm performans bileşenlerinde \% 5'den düşük olması, bireysel seviyede mutlak güvenirliğin kabul edilebilir düzeyde olduğunu göstermektedir. Ek olarak TMST protokolünde tüm performans bileşenleri için SKK'nın orta düzeyde ve TST protokolünden daha yüksek olması, içerisinde yön değiştirme bulunan tekrarlı maksimal eforların tekrarlı ölçümlerinin daha tutarlı ve değişkenliğin daha düşük olduğunu gösterir. Bu çalışmada her iki protokolün tekrarlı ölçümleri aynı zeminde, aynı malzeme (ayakkabı, şort) ve sirkadiyen ritmin (günün aynı saati) ve yorgunluğun etkisinden uzak (48-72 saat ara ile) ve rastgele sırada yapıldığ için bu bulgular, genç futbolcuların düz koşu şeklinde tekrarlı eforlarda koşu stratejisi geliştirdikleri şeklinde yorumlanabilir. Bu çalışmada her iki protokolde performans çıktıları için elde edilen bulgular, literatürde benzer çalışmaların bulgularıyla uyumludur. Profesyonel futbol oyuncularında yapılan 20 sn toparlanmalı 6 x $(20+20 \mathrm{~m})$ TMST testinde kısa süreli (48 saat aralıklı) güvenirliğin kabul edilebilir düzeyde olduğu rapor edilmiştir (Impellizzeri ve diğ., 2008). Adı geçen çalışmada TSZ ve EHSZ için VK_TH bu çalışmadaki TMST testinde olduğu gibi \% 5'den düşüktür (sırasıyla \% 0.8 ve \% 1.3). Castagna ve diğ (2018)'nin elit düzeyde olmayan genç futbolcularda (yaş=14.9 \pm 1.2 yıl) $30 \mathrm{sn}$ aktif toparlanmalı 5 x $30 \mathrm{~m}$ TST'de 48 saat ara ile yaptıkları tekrarlı ölçümlerde bu çalışmadaki TST'de olduğu gibi ikinci ölçümde TSZ'nın anlamlı derecede daha iyi $(\mathrm{p}<0.004)$, buna karşlık bu çalışmanın aksine EHSZ'nın benzer olduğunu rapor etmişlerdir. Bununla beraber TSZ ve EHSZ performans çıktılarının her biri için VK_TH \% 1.2 olarak rapor edilmiştir (Castagna ve diğ, 2018). Benzer şekilde okul futbol ve rugby takımında oynayan genç erkeklerde (Yaş = $15.3 \pm 0.3$ yll) $25 \mathrm{sn}$ aktif toparlanmalı ve $10 \mathrm{~m}$ lap'l1 7 x 30 m TST protokolünde EHSZ için $10 \mathrm{~m}$ sprintte \% 2.69 ve $30 \mathrm{~m}$ sprintte $\% 2.22$, TSZ için $10 \mathrm{~m}$ sprintte \% 2.01 ve $30 \mathrm{~m}$ sprintte \% 1.55 olarak hesaplanan varyasyon katsayısı bu çalışmada elde edilen bulgularla uyumludur. Çim hokeycilerde yapılan bir diğer çalışmada da 7 gün ara ile uygulanan $25 \mathrm{sn}$ aktif toparlanmalı 6 x 30 m TST'de TSZ için VK_TH \% 0.7 olarak rapor edilmiştir (Spencer ve diğ., 2006). Castagna ve diğ (2018) genç futbolcularda ve Wong ve diğ. (2012) ise kolej ve profesyonel futbolcular ile aktif bireylerden oluşan bir grupta kapalı salonda yaptıkları 25 sn aktif toparlanmal 6 × 20 m düz sprint protokolünde TSZ ve EHSZ için rapor ettikleri SKK değerleri hem Impellizzeri ve diğ., (2008) hem de bu çalışmada her iki protokolde elde edilen SKK değerlerinden yüksektir (Tablo 4). Bu bulgular tekrarlı 
sprint test protokollerinin SKK olarak güvenirliğinin testin uygulandığ yere, popülasyona ve protokole göre değiştiğini göstermektedir.

Tekrarlı sprint gibi yüksek şiddette lokomotor aktiviteler takım sporlarında müsabaka esnasında toplam oyun zamanının ya da kat edilen toplam mesafenin küçük bir yüzdesini oluşturmaktadır (Spencer ve diğ., 2004; Mohr ve diğ., 2003). Bununla beraber tekrarlı sprintlerin sayı ve sıklığı oyuncunun kalitesine ve mevkiye bağlı olarak değişir (Ferioli ve diğ., 2019; Póvoas ve diğ., 2014; Mohr ve diğ., 2003). Tekrarlı sprint yeteneği 30 sn veya daha kısa süreli aktif veya pasif toparlanma içeren bir aktivitedir ve eksik toparlanma tekrarlayan sprintlerde kasın kontraktil, metabolik ve nöromüsküler yapısında değişime neden olur (Sánchez-Sánchez ve diğ., 2018; Mendez-Villanueva ve diğ., 2008). Bu değişimler sonucu ortaya çıkan yorgunluk egzersizin tipine bağlıdır ve bisiklet ergometresinde uygulanan protokollerde \% 10-25, sahada uygulanan koşu protokollerinde \% 5-15 civarındadır (Girard ve diğ., 2011). Tekrarlı sprint uygulamalarında yorgunluğun değerlendirilmesi tekrarlayan sprintlerin kalitesindeki değişimi gözlemleme olanağı sunmaktadır. Yorgunluğun değerlendirilmesinde kullanılan yorgunluk indeksi (YI) veya sprintte düşüş yüzdesi (SDY), tekrarlı sprint test protokollerinde uygulanan protokolden ve katılımcı grubunun özelliklerinden bağımsız olarak test tekrar-test güvenirliği sistematik olarak düşük ve kabul edilemez düzeyde olan bir performans çıktısıdır (Castagna ve diğ, 2018; Wong ve diğ., 2012; Impellizzeri ve diğ., 2008; Hughes ve diğ., 2006; McGawley ve Bishop, 2006; Spencer ve diğ., 2006). Bu çalışmada da her iki protokolde elde edilen sprint değerlerinden 6 ayrı formülle hesaplanan yorgunluk düzeylerine ait güvenirlik düzeyi kabul edilemez düzeyde düşüktür (Tablo 6). Tekrarlı ölçümlerde bireysel seviyede değişkenliğin bir göstergesi olan VK_TH, TST protokolünde, \%28.3 - \% 129.4, TMST test protokolünde ise \% 31.4 - \% 119.2 arasında geniş bir aralıkta değiştiği saptanmıştır. Genç futbolcularda en düşük VK_TH, TST protokolünde YI'nin hesaplandığı Formül 4'de (\% 28.3), TMST test protokolünde ise yine YI'nin hesaplandığı Formül 5'de (\% 31.4) belirlenmiştir. Her iki protokolde de en düşük değişkenliği temsil etmekle beraber bu değerler, ölçümden ölçüme kabul edilebilir değişkenliğin üst sınırı olarak dikkate alınan \% 5'den (Hopkins, 2000) çok yüksektir. Tekrarlı sprint test protokollerinde yorgunluğu değerlendirmek için yaygın olarak kullanılan SDY'nin hesaplandığı Formül 3 için VK_TH, genç futbolcularda yukarıda belirtilen YI'nin hesaplandığı formüllere göre daha yüksek bulunmuştur. Takım sporlarında oynayan spor okulu öğrencilerinde yapılan 35 ve 65 sn toparlanmalı iki ayrı 12 x $30 \mathrm{~m}$ tekrarlı sprint test protokollerinde 7 farklı formülün test-tekrar test güvenirliğinin incelendiği bir çalışmada da bu çalışmanın bulgularına paralel olarak yorgunluk düzeylerinin tekrarlı ölçümlerde varyasyon katsayıları (35 sn toparlanma için \% 0.8-107.2, 65 sn toparlanma için \% 0.9-145.7) çok geniş bir aralıkta değiştiği rapor edilmiştir (Glaister ve diğ., 2008). Bu çalışmada genç futbol oyuncularında Formül 4 (TST'de en düşük) için hesaplanan VK_TH, Glaister ve diğg. (2008)'nin çalışmasında 35 sn toparlanmalı protokolde hesaplanana benzer, 65 sn toparlanmalı protokolde hesaplanandan düşüktür. Buna karşılık bu çalışmada içerisinde $180^{\circ}$ dönüş bulunan TMST test protokolünde Formül 5 (TMST'de en düşük) için hesaplanan VK_TH, Glaister ve diğ. (2008)'nin çalışmasında toparlanma süresinden bağımsız olarak her iki protokolde hesaplanandan önemli derecede düşüktür. Bu çalışmada diğer performans çıktıları ile karşılaştırıldığında her iki protokolden elde edilen yorgunluk düzeylerinin hesaplandığı tüm formüller için SKK değerleri de kabul edilemez düzeyde düşüktür (TST protokolü için -0.27 / 0.58, TMST test protokolü için -40 / 0.45) (Tablo 6). Genç futbol oyuncularında (6 x 30 m aktif toparlanmalı) (Castagna ve diğ., 2018), çim hokeycilerde (6 x $30 \mathrm{~m}$ aktif toparlanmalı) (Spencer ve diğ., 2006) ve genç okul takımı futbol ve rugby oyuncularında (7 x $30 \mathrm{~m}$ aktif toparlanmalı) (Oliver ve diğ., 2006) TST ve profesyonel futbolcularda $(6 \times(20+20 \mathrm{~m}) 20$ sn toparlanmalı) (Impellizzeri ve diğ., 2008) TMST protokollerinde yapılan güvenirlik çalışmalarında hesaplanan yorgunluk düzeylerinin test-tekrar test güvenirliği de bu çalışmada olduğu gibi kabul edilemez düzeydedir. Castagna ve diğg. (2018)'nin genç futbolcularda yaptıkları çalışmada 
bu çalışmadaki Formül 4'ü (Sprintte düşüş yüzdesi) kullanarak hesapladıkları yorgunluk düzeyi için SKK'nı 0.34, VK_TH \% 94 olarak rapor etmişlerdir. Benzer şekilde ilk ve son sprint değerlerinden hesapladıkları yorgunluk indeksi (bu çalışmadaki Formül 1) için SKK'nı 0.24, VK_TH \% 43.1 bulmuşlardır. Bu çalışmada 10 x 25 m TST protokolünde Formül 3 için SKK 0.10 ve VK_TH \% 49.9, Formül 1 için SKK 0.12 ve VK_TH \% 129.4'dür. Buna karşllık 180 dönüş içeren TMST protokolünün Formül 3 için güvenirlik parametreleri (SKK 0.21 ve VK_TH \% 41.6) Castagna ve diğ., (2018)'nin genç futbolcularda rapor ettikleri güvenirlik parametrelerine daha yakındır. Bu bulgular yorgunlukla ilgili güvenirliğin de test protokolüne, popülasyona ve kullanılan formüle göre değiştiğini göstermektedir.

Kas ve kanda LA konsantrasyonu egzersizin şiddetine bağlı olarak artar (Green ve diğ., 1983; Hughson ve diğ., 1987) ve 30-120 sn maksimal efor sonrasında 15-25 mmol..-1 değerine ulaşabilir (Goodwin ve diğ., 2007). LA konsantrasyonundaki artış egzersizin tipine ve kişiye bağlı olarak değişir ve dolaylı olarak kas içi anaerobik metabolizmanın enerji üretimine ne oranda katkıda bulunduğunu gösterir (Fox ve diğ., 1989). Genç futbolcularda $10 \mathrm{x}$ 25 m TST ve 10 x ( 2 x 12.5 m) TMST protokollerinde ölçülen kan LA değerleri, daha önce yetişkin ve iyi antrenmanlı futbol, hentbol ve basketbol oyuncularında 25 sn aktif toparlanmalı 6 × 25 m TST ve 6 x (2 x 12.5 m) (Buchheit ve diğ., 2010) ve yetişkin hentbol oyuncularında 20 sn pasif toparlanmalı 6 × (2 x 15 m) (Nakamura ve diğ., 2009) TMST protokollerinden $3 \mathrm{dk}$ sonra ölçülen kan LA değerlerine benzer, genç basketbolcularda (Yaş=16.8 \pm 1.2 y1l) 30 sn aktif ve pasif toparlanmalı 10 x 30 m TMST'den 3 dk sonra ölçülen LA değerlerinden düşüktür (Castagna ve diğ., 2008). TST ve TMST protokollerinde test sonu (sirasiyla 0.67 ve 0.76 ) ve 3 . $\mathrm{dk}$ (sirasiyla 0.75 ve 0.72 ) LA konsantrasyonlarının SKK orta düzeydedir. Buna karşılık her iki protokolde de $\mathrm{LA}_{\mathrm{TS}}$ ve $\mathrm{LA}_{3 . \mathrm{dk}}$ konsantrasyonları için hesaplanan VK_TH kabul edilebilir güvenirlik düzeyinden (\% 5 'den) yüksektir. Bu bulgu anaerobik metabolizmanın bir göstergesi olan kan LA yanıtlarının bireysel seviyede ölçümden ölçüme değişken olduğunu göstermektedir. TST protokollerinde fizyolojik cevaplar ile ilgili test-tekrar test güvenirlik çalı̧̧ma yok denecek kadar azdır. İyi antrenmanlı basketbol oyuncularında 5 yön değiştirme içeren 30 sn pasif toparlanmalı $10 \times 30 \mathrm{~m}$ tekrarlı sprint testinden 5-7 dk sonra ölçülen kan LA konsantrasyonu için test-tekrar test SKK (0.74), bu çalışmada her iki protokolde $\mathrm{LA}_{T S}$ ve $\mathrm{LA}_{3 . \mathrm{dk}}$ için elde edilen SKK değerlerine benzerdir (Zagatto ve diğ., 2017). Kan LA cevaplarının test-tekrar test güvenirliği ile ilgili yapılan çalışmalardan elde edilen bulgular, uzun süreli (düşük şiddetli) egzersizlerde SKK'nın nispeten düşük (0.77) (Aunola ve Rusko, 1984), Wingate testi gibi kısa süreli tek denemeli supramaksimal egzersizler sonrasında ise 0.90 'dan yüksek olduğu saptanmıştır (Jaafar ve diğ., 2014 ; Weinstein ve diğ., 1998).

Egzersizde ölçülen KAH, fizyolojik veya metabolik yüklenmenin boyutları hakkında bilgi veren önemli bir değişkendir. Bu çalışmada TST ve TMST protokollerinde ölçülen ortalama KAH, basketbolcularda birden fazla yön değiştirme içeren 10 x 30 m (Zagatto ve diğ., 2017), yetişkin hentbolcularda 6 x (2 x 15 m) (Nakamura ve diğ., 2009) ve iyi antrenmanlı takım sporcularında (Futbol, Hentbol, Basketbol) 6 × 25 m ve 6 x (2 x 12.5 m) (Buchheit ve diğ., 2010) tekrarlı sprint testlerinde ölçülen KAH'a benzerdir. Bu çalışmada her iki protokolde ölçülen $\mathrm{KAH}_{\text {test }}$ için SKK değerleri iyi düzeyde ve VK_TH \%5'den azdır. TMST protokolü ile karşılaştırıldığında toparlanmanın 3. dk'sında ölçülen $\left(\mathrm{KAH}_{3 . \mathrm{dk}}\right)$ test-tekrar test güvenirlikle ilgili katsayılar TST protokolündeki değerlerden yüksektir. Bu bulgular ve tekrarlı ölçümlerde KAH arasında anlamlı farkın olmaması, düz ve $180^{\circ}$ yön değiştirme içeren tekrarlı sprint protokollerinde $\mathrm{KAH}$ yanıtlarındaki değişkenliğin düşük olduğunu göstermektedir. Tekrarlı sprint testlerinde KAH yanıtlarının güvenirliği ile ilgili çalışma sayısı oldukça azdır. Basketbolcularda birden fazla yön değiştirme içeren 10 x 30 m tekrarlı sprint testinde test-tekrar test KAH yanıtlarında anlamlı fark saptanmamıştır (Zagatto ve diğ., (2017). Bununla beraber, hem submaksimal hem de maksimal şiddette ancak tekrarlı sprinte göre daha uzun süreli egzersizlerde elde edilen KAH yanıtlarının SKK değerleri (0.91-0.93) bu çalışmada elde edilen SKK'dan daha yüksektir (Aunola ve Rusko, 1984). 


\section{SONUÇ}

$\mathrm{Bu}$ çalışmanın sonuçları, genç futbolculara sahada uygulanan $10 \times 25 \mathrm{~m}$ TST ve $10 \times(2 \times 12.5 \mathrm{~m})$ TMST protokollerinin yorgunluk düzeyleri hariç performans çıktılarının güvenirliğinin yüksek olduğunu göstermiştir. $\mathrm{Bu}$ çalışma ayrıca içerisinde $180^{\circ}$ yön değiştirme bulunan TMST protokolünden elde edilen performans çıktılarının genç futbolcularda ölçümden ölçüme değişkenliğinin düşük olduğunu da göstermiştir. TMST protokolünde ölçülen TSZ, EHSZ ve EYSZ test-tekrar test ortalama değerleri arasında fark olmaması ve varyasyon katsayılarının çok düşük olması, $180^{\circ}$ yön değiştirme bulunan yüksek eforlu aktivitelerde kısa sürede öğrenmenin gerçekleşmediğini ya da performansa yansıyacak düzeyde olmadığını göstermektedir. Buna karşılık düz sprint içeren TST protokolünde, ikinci ölçümde tüm performans çıktılarında anlamlı iyileşme gözlenmesi bir öğrenme etkisinin ortaya çıktığını göstermektedir. Bu nedenle genç futbolcularda TST gibi içerisinde yön değiştirme bulunmayan test protokollerinde bir değerlendirme yapmadan önce alışma/öğrenme işlemi uygulanmalıdır. Her iki protokolde KAH yanıtlarının güvenirlik özelliği kan LA yanıtlarından yüksektir ve ölçümden ölçüme değişkenlik düşük düzeydedir. TMST protokolünde hem performans hem de fizyolojik yanıtların güvenirliği ile ilgili bulgular, bu protokolün bir antrenman planlaması içerisinde antrenman etkisini gözlemek veya bir deneme etkisinin fizyolojik sonuçlarını incelemek için TST protokolüne göre daha uygun olduğunu göstermektedir. Buna karşıllk bu çalışma her iki protokolde yorgunluk düzeyleri için elde edilen güvenirlik özelliklerinin kabul edilemez düzeyde olduğunu da göstermiştir. Bu parametre için tekrarlı ölçümlerden elde edilen değerlerin VK_TH'si, bir yorum yapmayı olanaksız kılacak kadar yüksektir. Bu nedenle TST protokollerinden elde edilen yorgunluk düzeyleri dikkatli değerlendirilmelidir. TST protokolünde yorgunluğun değerlendirilmesinde kullanılan 6 ayrı formülden hesaplanan yorgunluk düzeyleri için en düşük VK_TH Formül 4'de (\% 28.3), TMST protokolünde ise Formül 5'de (\%31.4) elde edilmiştir. Bu formüller genç futbolcularda tekrarlı ölçümlerde yorgunluğu değerlendirmek için kullanılabilecek en uygun yaklaşımdır.

\section{KAYNAKLAR}

1. Andrzejewski M, Chmura P, Konefal M, Kowalczuk E, Chmura J. (2018). Match outcome and sprinting activities in match play by elite German soccer players. J Sports Med Phys Fitness, 58(6), 785-792.

2. Atkinson G, Nevill AM. (1998). Statistical methods for assessing measurement error (reliability) in variables relevant to sports medicine. Sports Med, 26, 217-238.

3. Aunola S, Rusko H. (1984). Reproducibility of aerobic and anaerobic thresholds in 20-50 year old men. Eur J Appl Physiol Occup Physiol, 53(3), 260-266.

4. Bangsbo J, Nørregaard L, Thorsøe F. (1998). Activity profile of competition soccer. Can J Sports Sci, 16(2), $110-116$.

5. Barbero-Álvarez JC, Pedro RE, Nakamura FY. (2013). Validity of a repeated-sprint ability test in young soccer players. Sci sports, 28(5), $127-131$.

6. Beaven CM, Maulder P, Pooley A, Kilduff L, Cook C. (2013). Effects of caffeine and carbohydrate mouth rinses on repeated sprint performance. Appl Physiol Nutr Metab, 38(6), 633-637.

7. Ben Abdelkrim N, Castagna C, Jabri I, Battikh T, El Fazaa S, El Ati J. (2010). Activity profile and physiological requirements of junior elite basketball players in relation to aerobic-anaerobic fitness. J Strength Cond Res, 24(9), 2330-2342.

8. Bidaurrazaga-Letona I, Carvalho HM, Lekue JA, Santos-Concejero J, Figueiredo AJ, Gil SM. (2015). Longitudinal field test assessment in a Basque soccer youth academy: A multilevel modeling framework to partition effects of maturation. Int J Sports Med, 36, 234-240.

9. Bishop D, Spencer M, Duffield R, Lawrence S. (2001). The validity of a repeated sprint ability test. J Sci Med Sport, 4(1), 19-29.

10. Buchheit M, Bishop D, Haydar B, Nakamura FY, Ahmaidi S. (2010). Physiological responses to shuttle repeated-sprint running. Int J Sports Med, 31(06), 402-409. 
11. Castagna C, Abt G, Manzi V, Annino G, Padua E, D'Ottavio S. (2008). Effect of recovery mode on repeated sprint ability in young basketball players. J Strength Cond Res, 22(3), 923-929.

12. Castagna C, Lorenzo F, Krustrup P, Fernandes-da-Silva J, Póvoas SCA, Bernardini A, D'Ottavio S. (2018). Reliability characteristics and applicability of a repeated sprint ability test in young male soccer players. J Strength Cond Res, 32(6), 1538-1544.

13. Chmura P, Konefal M, Chmura J, Kowalczuk E, Zając T, Rokita A, ve diğ. (2018). Match outcome and running performance in different intensity ranges among elite soccer players. Biol Sport, 35(2), 197-203.

14. Deprez D, Fransen J, Lenoir M, Philippaerts RM, Vaeyens R. (2015). A retrospective study on anthropometrical, physical fitness and motor coordination characteristics that influence drop out, contract status and first-team playing time in high-level soccer players, aged 8 to 18 years. J Strength Cond Res, 29, 1692-1704

15. Deprez D, Valente-Dos-Santos J, Silva MJ, Lenoir M, Philippaerts R, Vaeyens R. (2015). Multilevel development models of explosive leg power in high-level soccer players. Med Sci Sports Exerc, 47, 1408-1415.

16. Di Salvo V, Baron R, González-Haro C, Gormasz C, Pigozzi F, Bachl N. (2010). Sprinting analysis of elite soccer players during European Champions League and UEFA Cup matches. J Sports Sci, 28(14),1489-1494.

17. Faude O, Koch T, Meyer T. (2012). Straight sprinting is the most frequent action in goal situations in professional football. $J$ Sports Sci, $30(7), 625-631$.

18. Ferioli D, Schelling X, Bosio A, La Torre A, Rucco D, Rampinini E. (2019). Match activities in basketball games: comparison between different competitive levels. J Strength Cond Res, 6. doi: 10.1519/JSC.0000000000003039.

19. Fox EL, Bowers RW, Foss ML. (1989). The Physiological Basis of Physical Education and Athletics. William C Brown Pub.

20. Girard O, Mendez-Villanueva A, Bishop D. (2011). Repeated-sprint ability—part I: Factors contributing to fatigue. Sports Med, 41, 673694.

21. Glaister M, Howatson G, Pattison JR, McInnes G. (2008). The reliability and validity of fatigue measures during multiple-sprint work: An issue revisited. J Strength Cond Res, 22(5),1597-1601.

22. Goodwin ML, Harris JE, Hernández A, Gladden LB. (2007). Blood lactate measurements and analysis during exercise: A guide for clinicians. J Diabetes Sci Technol, 1(4), 558-569.

23. Green HJ, Hughson RL, Orr GW, Ranney DA. (1983). Anaerobic threshold, blood lactate, and muscle metabolites in progressive exercise. J Appl Physiol, 54(4), 1032-1038.

24. Hopkins WG. (2000) Measures of reliability in sports medicine and science. Sports Med, 30(1), 1-15.

25. Hughes MG, Doherty M, Tong RJ, Reilly T, Cable NT. (2006) Reliability of repeated sprint exercise in non-motorised treadmill ergometry. Int J Sports Med, 27(11), 900-904.

26. Hughson RL, Weisiger KH, Swanson GD. (1987). Blood lactate concentration increases as a continuous function in progressive exercise. Journal of Applied Physiology, 62(5), 1975-1981.

27. Impellizzeri FM, Rampinini E, Castagna C, Bishop D, Ferrari Bravo D, Tibaudi A, Wisloff U. (2008). Validity of a repeated-sprint test for football. Int J Sports Med, 29, 899-905.

28. Jaafar H, Rouis M, Coudrat L, Attiogbe E, Vandewalle H, Driss T. (2014). Effects of load on Wingate test performances and reliability. J Strength Cond Res, 28(12), 3462-3468.

29. Koo TK, Li MY. (2016). A guideline of selecting and reporting intraclass correlation coefficients for reliability research. $J$ Chiropr Med, 15(2), 155-163.

30. Kopec BJ, Dawson BT, Buck C, Wallman KE. (2016). Effects of sodium phosphate and caffeine ingestion on repeated-sprint ability in male athletes. J Sci Med Sport, 19(3), 272-276.

31. McGawley K, Bishop D. (2006). Reliability of a 5 x 6-s maximal cycling repeated-sprint test in trained female team-sport athletes. Eur $J$ Appl Physiol, 98(4), 383-393.

32. Mendez-Villanueva A, Hamer P, Bishop D. (2008). Fatigue in repeated-sprint exercise is related to muscle power factors and reduced neuromuscular activity. Eur J Appl Physiol, 103(4), 411-419.

33. Michalsik LB, Aagaard P, Madsen K. (2013). Locomotion characteristics and match-induced impairments in physical performance in male elite team handball players. Int J Sports Med, 34(7), 590-599.

34. Miñano-Espin J, Casáis L, Lago-Peñas C, Gómez-Ruano MÁ. (2017). High speed running and sprinting profiles of elite soccer players. J Hum Kinet, 58, 169-176.

35. Mohr M, Krustrup P, Bangsbo J. (2003). Match performance of high-standard soccer players with special reference to development of fatigue. J Sports Sci, 21(7), 519-528.

36. Mujika I, Spencer M, Santisteban J, Goiriena JJ, Bishop D. (2009). Age-related differences in repeated-sprint ability in highly trained youth football players. J Sports Sci, 27, 1581-1590. 
37. Nakamura FY, Soares-Caldeira LF, Laursen PB, Polito MD, Leme LC, Buchheit M. (2009). Cardiac autonomic responses to repeated shuttle sprints. Int J Sports Med, 30(11), 808-813.

38. Oliver JL. (2009). Is a fatigue index a worthwhile measure of repeated sprint ability? J Sci Med Sport, 12(1), 20-23.

39. Oliver JL, Williams CA, Armstrong N. (2006). Reliability of a field and laboratory test of repeated sprint ability. Pediatr Exerc Sci, 18(3), 339-350.

40. Özdemir FM, Yılmaz A, Kin İşler A. (2014). Genç futbolcularda tekrarlı sprint performansının yaşa göre incelenmesi. Spor Bilimleri Dergisi, 25(1), 1-10.

41. Póvoas SC, Ascensão AA, Magalhães J, Seabra AF, Krustrup P, Soares JM ve diğ. (2014). Analysis of fatigue development during elite male handball matches. J Strength Cond Res, 28(9), 2640-2648.

42. Racinais S, Connes P, Bishop D, Blonc S, Hue O. (2005). Morning versus evening power output and repeated-sprint ability. Chronobiol Int, 22(6),1029-1039.

43. Rampinini E, Bishop D, Marcora SM, Ferrari Bravo D, Sassi R, Impellizzeri FM. (2007). Validity of simple field tests as indicators of match-related physical performance in top-level professional soccer players. Int J Sports Med, 28, 228-235.

44. Rienzi E, Drust B, Reilly T, Carter JE, Martin A. (2000). Investigation of anthropometric and work-rate profiles of elite South American international soccer players. J Sports Med Phys Fitness, 40 (2), 162-169.

45. Sánchez-Sánchez J, Bishop D, García-Unanue J, Ubago-Guisado E, Hernando E, López-Fernández J ve diğ. (2018). Effect of a repeated sprint ability test on the muscle contractile properties in elite futsal players. Sci Rep, 8(1), 17284.

46. Spencer M, Bishop D, Dawson B, Goodman C. (2005). Physiological and metabolic responses of repeated-sprint activities. Sports Medicine, 35(12), 1025-1044.

47. Spencer M, Fitzsimons M, Dawson B, Bishop D, Goodman C. (2006). Reliability of a repeated-sprint test for field-hockey. J Sci Med Sport, 9(1-2), 181-184.

48. Spencer M, Lawrence S, Rechichi C, Bishop D, Dawson B, Goodman C. (2004). Time-motion analysis of elite field hockey, with special reference to repeated-sprint activity. J Sports Sci, 22(9), 843-850.

49. Spencer M, Pyne D, Santisteban J, Mujika I. (2011). Fitness determinants of repeated-sprint ability in highly trained youth football players. Int J Sports Physiol Perform, 6(4), 497-508.

50. Stølen T, Chamari K, Castagna C, Wisløff U. (2005). Physiology of soccer: An update. Sports Med, 35, 501-536.

51. Weinstein Y, Bediz C, Dotan R, Falk B. (1998). Reliability of peak-lactate, heart rate, and plasma volume following the Wingate test. Med Sci Sports Exerc, 30(9), 1456-1460.

52. Wong Del P, Chan GS, Smith AW. (2012). Repeated-sprint and change-of-direction abilities in physically active individuals and soccer players: training and testing implications. J Strength Cond Res, 26(9), 2324-2330.

53. Zagatto AM, Ardigo LP, Barbieri FA, Milioni F, Dello Iacono A, Camargo BHF ve diğ. (2017). Performance and metabolic demand of a new repeated-sprint ability test in basketball players: Does the number of changes of direction matter? J Strength Cond Res, 31(9), 24382446. 